What really matters?

Ring, Adele; Jacoby, Ann; Baker, Gus; Holmes, Emily; Hughes, Dyfrig; Kierans, Ciara; Marson, Anthony

\title{
Epilepsy and Behavior
}

Published: 01/06/2019

Peer reviewed version

Cyswllt i'r cyhoeddiad / Link to publication

Dyfyniad o'r fersiwn a gyhoeddwyd / Citation for published version (APA):

Ring, A., Jacoby, A., Baker, G., Holmes, E., Hughes, D., Kierans, C., \& Marson, A. (2019). What really matters? A mixed methods study of treatment preferences and priorities among people with epilepsy in the UK. Epilepsy and Behavior, 95, 181-191.

Hawliau Cyffredinol / General rights

Copyright and moral rights for the publications made accessible in the public portal are retained by the authors and/or other copyright owners and it is a condition of accessing publications that users recognise and abide by the legal requirements associated with these rights.

- Users may download and print one copy of any publication from the public portal for the purpose of private study or research.

- You may not further distribute the material or use it for any profit-making activity or commercial gain

- You may freely distribute the URL identifying the publication in the public portal ?

Take down policy

If you believe that this document breaches copyright please contact us providing details, and we will remove access to the work immediately and investigate your claim. 
What really matters? A mixed methods study of treatment preferences and priorities among people with epilepsy in the UK

Authors:

Adele Ring ${ }^{1}$, Ann Jacoby ${ }^{2}$, Gus Baker ${ }^{2}$, Emily Holmes ${ }^{3}$, Dyfrig Hughes ${ }^{2,3}$, Ciara Kierans ${ }^{1}$, Anthony Marson $^{2}$

1.Department of Public Health \& Policy, University of Liverpool, UK; ${ }^{2} \cdot$ Department of Molecular and Clinical Pharmacology, University of Liverpool, UK; ${ }^{3}$ Centre for Health Economics and Medicines Evaluation, Bangor University, Wales.

Key learning points:

- We explored UK patient preferences for treatment of epilepsy

- Our study involved a qualitative component, followed by a large-scale survey

- Participants had clearly-formed views and preferences for care, reflecting their personal characteristics and life contexts

- Practitioners need to be mindful of these in discussions about care

- Patients deserve access to high quality evidence about effectiveness of different treatments

\section{Key words:}

Patient preferences; Life context; Treatment benefits and costs; Antiepileptic drugs; Surgery;

Psychological/neuropsychological treatments; Complementary therapies 


\section{Abstract}

The widening range of treatment options for epilepsy, and their potential outcomes, mean decisions about treatment for people with epilepsy are often complex. While antiepileptic drugs (AEDs) represent the mainstay of treatment, other potential non-drug interventions are gaining in importance. These treatments all have the potential for harming those using them, as well as bringing benefits.

This study examined the views and experiences of people with epilepsy (PWE) about a range of treatment options. We used both qualitative and quantitative approaches - a series of depthnarrative interviews, followed by a large-scale survey. Treatment options and healthcare priorities deemed important by at least $10 \%$ of interview participants were then addressed as a series of statements in the follow-on survey questionnaire. Quantitative responses supported health care priorities identified through the qualitative interviews.

The key goal of treatment among study participants was to be able to live 'a normal life'. Important physical, psychological and life benefits of treatment were identified - most being the direct consequence of improved seizure control. One psychological benefit, reduced worry, was also identified as an important treatment goal.

All participants viewed AEDs as appropriate first-line treatment; and since adverse effects of AEDs had implications for individual levels of daily function and wellbeing, their appropriate management was considered important. In contrast, surgery was almost always regarded as the treatment of last resort. Despite lack of research evidence supporting their use, participants were interested in complementary therapies as adjunctive treatment and a means of coping with having epilepsy, with yoga and meditation of particular interest. An important finding was the desire for targeted services to help with memory problems, as was the call to increase availability of psychological/counselling services.

Our findings emphasise the importance of providing treatment responsive to the life context of individual patients. They highlight not only the level of demand for specific treatment options, but also the need for high-quality evidence to support future investment in their provision.

Word Count: 319 


\section{Introduction}

Neurological conditions are a key priority for research into patient care in the UK (1). Epilepsy is the most common of serious neurological conditions, affecting an estimated six million people in the European Region and around 600,000 people in England (2,3), who have to live daily with its sociomedical repercussions. Most people given a diagnosis of epilepsy are treated with antiepileptic drugs (AEDs), of whom $60-70 \%$ will achieve remission from seizures $(4,5)$. The remainder will continue to have seizures and experience the consequences of a chronic disabling and potentially stigmatising condition $(6,7)$. Achieving remission, however, may come at the cost of adverse medication effects, including common dose-related effects such as weight gain or low mood, rare but potentially lifethreatening events such as psychosis, and long-term effects including memory problems. A third of people treated for epilepsy are women of childbearing age; and a growing body of evidence shows their children to be at increased risk of congenital abnormalities and neuro-developmental problems (8-11).

While AEDs are the mainstay of clinical treatment for epilepsy, other potential non-drug interventions of increasing importance include surgery (12) and vagal nerve stimulation (13). Recently, there has been a resurgence of interest in dietary control of refractory seizures (14-16). The role of psychological treatment programmes for seizure control, such as Relaxation Therapy, Cognitive Behavioural Therapy and Biofeedback, is also being explored (17-19); as is that of alternative therapies such as yoga (20) and Chinese traditional medicine (21). For management of common co-morbidities and quality of life impacts, available treatments include psychological and educational interventions and counselling $(18,19,22-27)$. All these treatments have potential costs to those using them, as well as benefits. For example, surgery has been shown to have potential detrimental effects for cognitive function and memory (28); and psychosocial outcomes are poorer for those not achieving complete seizure freedom (29). Likewise, though tolerability to it generally improves over time, there are short-term adverse effects associated with VNS (30); and dietary control requires careful monitoring to avoid possible nutritional deficits (31).

The wide range of treatment options and their potential outcomes mean treatment decisions for people with epilepsy (PWE) are often complex, involving careful consideration. That patients' views about benefits and harms may differ from those of clinicians has been shown across a range of conditions (32-34). The cultural shift in the UK National Health Service from 'medical dominance to managed consumerism' (35) is reflected in policy documents highlighting the need for care to be planned around the specific needs and choices of individual patients $(36,37)$ and to ascertain views and goals of users with regard to processes and outcomes of care. Users are now seen as having a central role in defining priorities for service provision and assessment of outcomes (38). Data about their preferences for treatments and treatment outcomes are important both in health technology assessment and healthcare prioritising initiatives (39).

To date, little systematic empirical research has been undertaken to assess the views of PWE about treatment interventions and outcomes that are important to them. For example, the commonly applied criterion of success in drug trials is a $50 \%$ reduction in seizure frequency. This criterion is, however, arbitrary and not derived from judgements of PWE themselves (though previous work (40, 41) shows a much greater reduction is required for meaningful QOL impacts). Similarly no attempt has been made to include patients' views in definitions of what constitutes meaningful difference or lack of difference between treatments. A small number of primary research-based studies have addressed these issues (42-47) and two Cochrane reviews have touched tangentially on them 
$(48,49)$. However, understanding of what PWE themselves regard as key issues around the management of their condition and key outcomes of that management rests on an extremely thin evidence base.

The over-arching aim of the project we report here was to explore the views and understandings about, and preferences for treatment, of adults with epilepsy; and hence address the question as to what constitutes appropriate epilepsy management. Since the implications of having epilepsy can vary considerably for different clinical trajectories and life contexts, we addressed these issues across three different patient subgroups, namely:

a) adults with a recent diagnosis of epilepsy (diagnosis made at least three months but not longer than 12 months ago)

b) adults with established epilepsy (diagnosis made more than 12 months ago) and on antiepileptic treatment

c) as a separate group, women of childbearing potential (18 to 50 years) with early or established epilepsy.

Our specific research objectives were to explore:

1. which treatment interventions are considered important by people with epilepsy; and whether and how different patient subgroups prioritise different interventions;

2. which outcomes of treatment interventions are considered important by people with epilepsy; and whether and how different patient subgroups prioritise different outcomes.

The study received ethics approval from the UK National Research Ethics Service Committee North West on $3^{\text {rd }}$ May 2011.

\section{Methods}

\section{Overall study design:}

To address the above objectives, our study involved two separate phases. In Phase 1, a series of qualitative interviews were conducted with a small number of participants. This was followed in Phase 2 by a large-scale quantitative survey.

In the first phase, we used in-depth-narrative interviews (50) to provide insights into how individual patient circumstances and life experience condition their concerns about treatment and its outcomes (51), followed by topic guided questions and a ranking exercise to examine which treatment interventions and outcomes were deemed important, and why. For this latter part of the interviews, participants were provided with a brief summary of each treatment along with information about its effectiveness - the aim being to allow those without any personal experience or knowledge of the treatment possibilities to give each meaningful consideration (see examples in Appendix 1). Expressed preferences were considered in relation to AEDs, surgery, vagal nerve stimulation, psychological interventions, including support for memory problems and use of complementary therapies.

In the second phase, a web-based survey, hosted on the website of the UK patient organisation, Epilepsy Action, examined the generalisability of findings from the qualitative interviews and allowed further exploration of treatment preferences. Issues raised by $10 \%$ or more of participants in the 
qualitative study formed the basis of a series of preference statements for the survey, the precise wording of which was based on their own words.

This second phase also involved a series of discrete choice experiments to elicit preferences specifically with regard to the attributes of different AEDs and to explore maximally acceptable risk for each AED outcome. The results from the DCE are reported separately elsewhere (52).

Ethical approval for the study was given by the UK Health Research Authority NRES Committee North West.

\section{Sampling and recruitment}

In the first phase we aimed to recruit a maximum of 60 patients, around 20 patients from each of the three groups described above. Purposive sampling methods (53) were used to achieve maximum variation in clinical and socio-demographic characteristics within each group. Inclusion and exclusion criteria are shown in Box 1.

\section{Inclusion criteria}

- An outpatient at one of three major UK epilepsy centres and meeting criteria for one of three defined groups (see above)

- Aged 18 years and over

- No other long-term health conditions

Exclusion criteria:

- Aged under 18 years

- With learning difficulties sufficient as to make required tasks unreasonable

- Non-English speaker

- Currently participating in other research

- Unable to provide informed consent

\section{Box 1: Sampling criteria for Phase 1}

Participants were identified by clinical staff at three specialist epilepsy centres in the UK. Staff approached 129 people based on the study inclusion/exclusion criteria (staff reviewed clinical notes of listed patients in advance of clinic attendance to check for potential eligibility). Sixty-two (48\%) of those approached registered their interest in participating in the study and were contacted. Five people subsequently declined to take part, contact was lost with one person and 56 people consented. Prior to the interview participants received a copy of the study information leaflet. Before the interview commenced, the purpose of the interview, freedom to withdraw, the issues of anonymity and risk and audio recording of the interview were discussed; and participants had the opportunity to ask any questions and have these answered. Participants then provided written consent for participation. Interviews were conducted in participants' own homes or at an alternate venue of their choosing. All interviews were conducted by the same researcher (AR). The majority of interviews were between one and two hours in duration. The participant sample comprised 29 males and 27 females, with an age range of $20-76$ years (mean age: 40.12 years). Twenty-three participants had a recent epilepsy diagnosis and 33 established epilepsy. Twenty-two were women defined as 'of childbearing potential', of whom seven had a recent diagnosis and 15 had established epilepsy. Further details of the socio-demographic characteristics of the sample are given in Table 1. 
All participants were currently taking anti-epileptic drugs (AEDs). Of the 23 participants with early epilepsy 18 were on monotherapy. The two most common AEDs taken by people with early epilepsy were lamotrigine and levetiracetam. Of the 33 participants with established epilepsy one third were on monotherapy. The two most common AEDs taken by participants with established epilepsy were lamotrigine and carbamazepine. Of the 22 women of childbearing potential, 11 were on monotherapy. The two most common AEDs taken by women of childbearing potential were lamotrigine and levetiracetam.

\begin{tabular}{|c|c|c|c|}
\hline & $\begin{array}{c}\text { Recent epilepsy } \\
\text { diagnosis } \\
\mathrm{N}=16\end{array}$ & $\begin{array}{l}\text { Established epilepsy } \\
\qquad \mathrm{N}=18\end{array}$ & $\begin{array}{c}\text { WOCBP } \\
\mathrm{N}=22\end{array}$ \\
\hline Gender = Female & 3 & 2 & 22 \\
\hline Mean age (years) & 47.6 & 40.3 & 34.6 \\
\hline Occupational status & & & \\
\hline Full time work & 7 & 8 & 11 \\
\hline Part time work & 1 & 2 & 2 \\
\hline Permanently & 4 & & 4 \\
\hline sick/Incapacity & & 2 & \\
\hline Unemployed & 1 & 3 & 1 \\
\hline Retired & 3 & 1 & \\
\hline Student & & 1 & 1 \\
\hline Housewife & & 1 & 2 \\
\hline Voluntary work & & & 1 \\
\hline
\end{tabular}

Table 1: Study sample characteristics, Phase 1

* WOCBP $=$ Woman of childbearing potential.

Participant inclusion criteria for the Phase 2 survey were: adults self-reporting being aged 18 or over and diagnosed with epilepsy by a doctor. For the purposes of the Discrete Choice Experiments (DCEs), potential respondents were directed to one of three versions of the questionnaire, depending on which of the three patient groups they defined themselves as belonging to (for full details of the DCE methods, see 52). As for the qualitative study, survey respondents were provided with brief descriptions of each treatment and a statement about the evidence of its effectiveness. They were asked first to record whether or not they had any personal experience of trying a specific treatment and how helpful they had found it (using a four-point Likert response scale, 'did not help at all' to 'helped a lot'); and then to register their agreement/disagreement with each preference statement (using a five-point Likert response scale, 'strongly agree', 'agree somewhat', 'don't know', 'disagree somewhat', 'strongly disagree'). Survey respondents were asked to provide basic clinical and socio-demographic information about themselves (age, gender, epilepsy duration, current seizure frequency/status) to contextualise their responses.

\section{Data analysis}

Phase 1 interviews were tape-recorded, with agreement of participants, and transcribed verbatim. Transcripts were imported into NVivo software (QRS Int Pty Ltd) for ease of management and coding of transcript data (54). Early transcripts were read and discussed by AR and AJ. Salient concepts were identified through a process of 'open coding' (55). Codes were categorised thematically and relationships between the themes were identified through a process of constant comparison (56). The themes included both in-vivo concepts articulated by participants themselves (55) e.g. 'a normal life' and researcher-defined concepts such as 'psychological distress'. Through this process a 
thematic framework was developed and applied to all transcripts. Each participant was assigned a unique serial number (PSN). The analysis aimed to identify categories common across all three patient subgroups and any specific to each; and to identify any commonalities and/or differences by other clinical and non-clinical factors. In the event, patient subgroup did not emerge as critical to preferences in the analysis, so is not the focus of the findings reported here.

Data for the survey were analysed in SPSS (IBM Corporation, Somers, NY) using frequencies and descriptive statistics.

\title{
Phase 1 Findings
}

\section{Introduction to preference findings: What does it mean to live life with epilepsy?}

Epilepsy is not a single clinical condition, but rather a spectrum of seizure severity associated with a range of psychosocial impacts (57). While the clinical features of epilepsy are central to the experience, epilepsy and its treatment do not occur in a vacuum, but within a unique set of life circumstances, exploration of which can help us to understand its differential impact on people's lives (58).

Participants in this study described the different ways that epilepsy intruded in their lives including disrupting their working life, social activities, daily routines and relationships and affecting their physical and psychological wellbeing. Impact in one area of daily life often had knock-on effects for other aspects. For example, many participants spoke about the wide reaching impact of not being allowed to drive, including on getting to work, the type of work they were able to do and the organisational aspects of work. Driving was an important aspect of 'independence' and having to rely on other people was an undesirable outcome of having epilepsy for many participants. The context within which loss of the ability to drive was experienced was important, as one participant described:

\begin{abstract}
'Yes [frustrating] because you are relying - I know it's not important to most people - but you are relying on public transport...there is always cancellations, I mean it took me 3.5 hours to get to work the other day and I only work in [town] if I had my car it would have took me 20 minutes...I was so late for work.... A lot of posts that are coming up that I apply for I can't have because I have had my driving licence ceased, and that has been a huge impact on my life. Because now I have to walk a mile and half to the train station and get 2 trains to work, and then after work I get 2 trains to the nursery, to pick the kids up and spending 3 hours a day commuting' [PSN 055, Recently diagnosed epilepsy, WOCBP]
\end{abstract}

The disruption epilepsy brought to daily life was a major contributory factor to participants' psychological status, including feelings of unhappiness, low mood and depression. Some participants also attributed their distress to AED treatment, because of the impact of adverse effects on aspects of their everyday life. For example, participants cited possible problems with cognitive functioning, such as memory problems; and physical problems such as weight gain.

'The side effects of the Epilim has just knocked me for six....because the weight gain....it is just so depressing, it really is, and it's unbelievable what it does to you. It does, you know what I mean, it knocks your confidence.' [PSN 006, Established epilepsy, WOCBP]

An important concept in understanding epilepsy impact was that of 'a normal life'. Some participants referred to this when talking about the benefits of treatment - usually, though not always, linked to 
seizure control. A normal life involved being able to carry on with things as they had been prior to experiencing seizures - including continuing as usual in employment, being able to look after children/family, and being able to take part in sporting and social activities. While achieving a sense of normalcy was often linked to gaining complete seizure control, one participant described how even a reduction in the frequency of their seizures and the debilitating after-effects had contributed to a sense of 'normality' - by extending the time where they were well enough to be with their family. The types, as well as the frequency, of seizures participants experienced were also important in understanding epilepsy impact (Box 2).

Obviously the seizure happened in work you see, that is a big factor. .... I wanted to see if I could get a letter from [hospital] saying [name] is now on medication and he can live a normal life and he is fine to do this, he is fine to do that... and then work to say right ok, we will tick our box. Carry on like you were before. [PSN 023, Recently diagnosed epilepsy, Male]

Once I am free [of seizures] for a few weeks, a couple of months, then probably [I can] start getting back into the old way of life and just not having to worry all the time...you will be able to just live your life normally again... I will be able to look after my kids, just not having to have somebody here all the time, while my kids are here. [PSN 016, Established epilepsy, Male]

I got on the gabapentin and it even though it didn't stop my fits it changed my life drastically.... got some sort of what people would call normality because I had never had that before....it gives me longer to be me and longer to be with my kids and things like that. [PSN 007, Established epilepsy, WOCBP]

The generalised seizures are by far the most, the ones that have the most impact on my ability to function on a daily basis, the partials you can pass off sometimes as just depending on how long they go for.... the generalised one, the recovery time as well is excessive for me, I need to sleep for hours, so, if that happens at work or when you are out, it is a, it can just ruin a day you just lose a day basically, which is not good for me. [PSN 056, Recently diagnosed epilepsy, WOCBP]

\section{BOX 2: Living life with epilepsy}

In describing their experience of epilepsy participants frequently referred to their individual circumstances - throwing into stark relief the importance of the lived context of epilepsy in understanding its impact. Not surprisingly then, this context (including both clinical and social factors) was also important in understanding participants' preferences for treatment.

\section{Treatment preferences}

In this section we focus specifically on participants' views, preferences and decisions about specific treatments. These included: (i) Medical treatments (drug treatment, brain surgery, vagal nerve stimulation and the ketogenic diet), (ii) psychological treatments (cognitive behaviour therapy and aids for memory problems) and (iii) complementary therapies (Meditation, Yoga, Aromatherapy, Biofeedback, Chinese herbal medicine and Acupuncture). All participants had experience of treatment with anti-epileptic drugs (AEDs), a small number had undergone brain surgery and a few had tried or were currently using VNS. 
In considering what was important about treatment and how they felt about different treatment options, our participants thought about how their life had been or might be affected by treatment. Some referred to their experience of treatment as being effective in stopping seizures, others reported examples of treatments either being unsuccessful or having had negative outcomes. The likely risks of treatment were a key consideration, those associated with medication withdrawal (further seizures) and brain surgery (brain damage and even death) being particularly challenging.

(i) Medical treatments: Antiepileptic drugs

It was evident from both the narrative accounts and direct questioning that AEDs were the preferred option for most participants and it was only where AED treatment had proven unsuccessful that other types of treatment were considered. However, specific decisions including switching AEDs and increasing dosages were highly individual, highlighting the importance of both clinical and psychosocial contexts of treatment decisions. For example, one participant described how they had requested a return to a previous AED when a change to their medication was followed by a return of more 'worrying' seizures, leading to injury. Another participant had requested of their clinician that the dose of their current AED be increased and the introduction of a second AED following failure of the current regimen to substantially reduce the frequency of their seizures - for this participant reducing anxiety and getting back to driving were key goals of treatment. And while most participants were willing to tolerate some negative effects of AEDs in order to achieve seizure control, there was a tipping point at which the negative effects of AEDs for daily living outweighed any potential gains (Box 3). For those who were seizure-free, whether or not to withdraw from AED treatment was another risk issue to be negotiated, given the potential daily life repercussions of a relapse to seizures (Box 3).

I kind of take most side effects if it means that I can get my licence back and become seizure free and stop that worry... about fitting and, the side effects of tiredness and mood swings and irritability pale into insignificance compared to worrying about making an idiot of yourself in the town centre, by collapsing on the floor, or worrying about your daughters hurting themselves or not being able to drive. [PSN 054, Recently diagnosed epilepsy, Male]

She [ESN] said to, try and introduce one more [tablet], I literally have tried but I would be in bed by 6.30 before the kids actually go to bed...I don't think that's a life really ....so the best medication is the one that is going to have less impact your life. [PSN 007, Established epilepsy, WOCBP]

I was taking lamotrigine and it wasn't working by itself, so they put me on another drug.... I had no idea that I was so - I think aggressive would be the word, until... [business partner] turned round and said I can't deal with you snapping at me anymore...I said right ok I will come off it.... I felt absolutely awful, as you can imagine, which is why I came off the drugs so I have been a lot more ill...but I don't care, quite frankly as long as we are ok. [PSN 020, Established epilepsy, WOCBP]

The difficulty then is, ok, I might try without medication but if another seizure results then I can't drive again for at least 12 months, and if I have got a young child [husband] works away a lot, and I haven't got a vehicle how does that impact me? You know, my family don't live here, they all live far away so I can't rely on family to help me get around - so it sounds daft, but one sort of small thing like that has so many ramifications....certainly from my point of view it's not a hugely difficult decision because I don't really have any side effects on the medication. [PSN 014, Established epilepsy, WOCBP] 


\section{Box 3: Preferences about AEDs}

A key theme in the data was that AED side effects (SEs) were an important cause for concern - with participants expressing a variety of reasons for their concerns about particular side effects of medication. Important sub-themes (reasons for concern described by many participants) were:

(i) SEs as psychologically distressing

Side effects experienced as psychologically distressing either had a direct impact on psychological wellbeing (AEDs seen to be the cause of feelings of depression/anxiety/agitation) or indirectly (side effects associated with other symptoms such as weight gain, hair loss or word-finding difficulties that caused further psychological distress.

(ii) SEs as disrupting functionality

Many participants spoke about the disruption to daily functioning as a consequence of AED side effects. Side effects that were particularly problematic in terms of daily functioning included: tiredness, memory problems and difficulties with concentration.

(iii) SEs as exacerbating other current or past difficulties

Participants were particularly concerned about side effects that could further exacerbate current or past difficulties. Depression was the side effect that most participants found concerning and wished to avoid either because they had experienced depression in the past or because they were currently experienced bouts of depression. A number of participants also expressed concern about the possibility of experiencing depression based on their perception of depression as a debilitating condition. Concentration and memory problems, nervousness, dizziness, headaches, tiredness and anger were also symptoms participants were concerned about based on their current or past experience. For some people, symptoms such as nervousness (stress) and dizziness were identified as possible triggers for their seizures and hence their concern that such symptoms might be associated with AEDs. Other participants associated some symptoms with having epilepsy (e.g. memory problems) and as such were concerned that these symptoms might also be associated with AEDs.

(iv) SEs as impacting on 'others'

Feelings of anger and aggression were of concern to participants because of the perceived impact this would have on other people in particular family members. Several described the impact of such feelings for personal and work relationships, others described it not being in their nature. For a small number of participants depression was also a side effected that they would be concerned about because of the perceived impact on close family members.

(See Box 4).

(v) Concerns specific to pregnancy

Adverse effects of AEDs had the added concern for women of child bearing potential of risk of harm to their unborn child should they become pregnant. As such, treatment decisions in relation to AEDs involved an added layer of complexity (see Box 4): 
Obviously the side effect of this tablet now, it is an increased dosage but it's stopped, well, it's decreased my seizures - but obviously the result of that is obviously the anxiety...you will get that with the Keppra and the it's a known side effect.... it's not a nice thing in general, anxiety.... you want to get on with things and you want to do things, and you just, but it's building up (PSN 036, Established epilepsy, Male).

Then problems remembering things...I have to say doesn't really affect me at all but, I would start to get very worried if I started not being able to remember things...it would just make me feel like my brain was going really if that started happening I would seriously have to consider.... what is going on to be honest (PSN 009, Established epilepsy, Male)

Feelings of anger or aggression - I think that maybe I wouldn't want to have that problem...it wouldn't be a bit fair on my wife, she would take the brunt of it wouldn't she (PSN 039, Recently diagnosed epilepsy, Male).

'I wanted to reduce the risk of anything happening to the baby. But I didn't want to, you know, like double my chance of having a fit and losing the baby altogether, if you know what I mean, so I sort of had to balance baby over me' (PSN 007, Established epilepsy, WOCBP)

\section{Box 4: Expressed concerns about AED adverse effects}

\section{(ii) Medical Treatments: Surgery}

Risk was a key theme in relation to brain surgery. Because it was seen as a particularly risky option it was completely ruled out by some participants. However, participants' assessments of risk were highly contextualised, their individual life circumstances being key (Box 5). In the majority of instances where surgery was considered a potential option, it was almost always a last resort, where other approaches had proved unsuccessful in controlling seizures adequately or generated other difficulties (Box 5).

I am a mum, I said do you think I am going to put myself through this [operation], when there is a risk of death, I know there is a risk of death when I have a fit, but I am not actually going to put myself into an operation knowing there is a risk of death and I have got a little one, so I said, thank you, but no [PSN 003, Established epilepsy, WOCBP].

I still live in hope that, you know, the medication will settle it down. If it doesn't... I would want information about what options there are for me because I don't, I am not sure that I want to be taking lots and lots of different types of medication....if, you know, they could find what was causing it...there might be some other options open to me such as surgery, or this nerve stimulation or whatever, and so certainly I would consider those you know if it was possible [PSN 047, Recently diagnosed epilepsy, WOCBP].

It's looking down towards the surgery route now....the medications I have tried, you know, I have been up to and around and actually above the maximum dosages....the medications just don't seem to have had an impact on the grand mal seizures, the full seizures... actually [I'm] quite pleased .... I'm actually having the assessments... I have spoken to two people who have had [type of surgery], and it's worked well for them [PSN 031, Established epilepsy, Male]. 
(iii) Medical Treatments: Vagal Nerve Stimulation (VNS)

As for brain surgery, risk was an important theme in relation to VNS. Although some participants were willing to consider it as a form of treatment VNS, like brain surgery, was generally seen as a secondary option; and for some participants, the invasiveness of the procedure and lack of evidence of effectiveness in completely controlling seizure meant it was not a viable one.

(iv) Psychological/Neuropsychological Treatments

The benefits of psychological and neuropsychological approaches were key themes in the data. Given the negative psychosocial consequences of epilepsy described by many participants, access to psychological support was considered an important treatment option. Participants advocating psychological support ('having someone to talk to') considered the main benefits to be in reducing distress and helping people to cope with having epilepsy. Some people were also of the view that psychological support might help with seizure control, where stress was a trigger factor (Box 6 ).

Many participants (including those with more recently diagnosed epilepsy) highlighted the negative impact of epilepsy and drug treatment on memory; and so considered help with memory problems to be an important treatment option. For example, one participant described the wide reaching impact memory loss was having and the potential serious consequences for their working life, which in turn was contributing to the psychological toll of epilepsy (Box 6).

\section{v) Complementary therapies}

Key themes with regard to use of complementary therapies were their value in managing and coping with epilepsy. Such therapies, in particular Meditation and Yoga, were viewed as potentially useful in reducing stress and aiding relaxation in the context of epilepsy and its effects - and hence were particularly valued by participants who considered stress to be a potential seizure trigger. Other participants too were interested in these types of therapies, seeing their value as lying in helping people to cope with epilepsy and its effects (Box 7).

I think doctors and specialists think about the physical benefits with your medication and stuff like that, but I think the psychological issues get very overlooked and they don't get treated - so I think with good psychological help, it reduces the amount of fits that you have or the stress that you have or the stress that can trigger the fits - so I think it's very beneficial that you have some sort of psychological help (PSN 007, Established epilepsy, WOCBP].

Next I would put problems remembering things, because that really does affect work and it affects home life as well - you know, when I am supposed to do things, just everyday things, and I forget to do it, it has a huge impact ....if I forget things in work it's serious...God, something could go wrong, and something bad could happen.... and all because I forgot to do something. So that does worry me.... and that makes me depressed [PSN 055, Recently diagnosed epilepsy, WOCBP]. 
Yoga, it's not something I have tried myself but....it's something that I might like to try in terms of helping to gain a form of relaxation. As I said before.... stress can be a trigger for seizures, so that can be a great way of managing stress [043, Established epilepsy, Male].

The yoga and the acupuncture, the herbal medicine, meditation, yes, I think I would see that more as being a treatment for the way that you feel, rather than controlling your actual condition,... it wouldn't cure you of [epilepsy] but it might make you feel better [PSN 052, Recently diagnosed epilepsy, WOCBP].

Box 7: Preferences for complementary therapies

\section{Summing up - the complexity of treatment decisions}

Through the findings presented above we aim to demonstrate the multitude of factors that can influence individual treatment decisions. Their experiences of treatment and assessments of treatment benefits and adverse consequences clearly influenced participants' preferences and decision-making. In the absence of adverse effects and taking account of the consequences of continuing seizures for everyday life, the decision to take AEDs was a relatively straightforward one. Where seizures had become intractable and the negative impacts of increasing AED dosage far outweighed the potential for achieving seizure control, limiting the disruptive effects of treatment on everyday life became a key goal.

While treatment with AEDs was the preferred option for the majority, some participants, even early in their epilepsy trajectory, expressed willingness to consider others, should their seizures not be well enough controlled by medication. However, the limited evidence for success of some interventions, the risks involved and their perceived 'invasiveness' meant other participants were adamant that some treatments were not viable options for them. With regard to non-clinical treatments, a considerable number of participants highlighted problems with their memory and how this affected their everyday life, such that support to improve memory problems was seen as potentially highly beneficial. Psychological therapies were also considered important in managing the negative impact of epilepsy on sense of wellbeing. Similarly, complementary therapies were considered potentially helpful to reduce stress - sometimes identified as a trigger for seizures - and as an aid to relaxation.

Although used as a means to identify study participants, our analysis of the qualitative material highlighted that patient subgroup did not emerge as critical to preferences: all the issues described were endorsed by participants across all our sampled groups. However, for one group, women of childbearing potential, the complexity of treatment decisions was compounded by preferences over contraception and by their understanding of the need to balance potentially competing risks to themselves versus any unborn child. As has been shown elsewhere (59) and was clearly articulated by the women in this study, they faced the additional dilemma of whether to continue taking AEDs, with possible negative effects for pregnancy outcomes, or discontinue AEDs and risk an increased frequency of seizures.

\section{Phase 2 Study Findings}

Four hundred and fourteen people responded to the survey ( 7 by paper). Of these 401 started, though not all completed, the survey questionnaires. The numbers completing the preference statements ranged from 323 to 331 . 
The median age of the sample was 37 years (range 18-79); and 68\% of the respondents were female. The majority of respondents co-habited; and just over half were employed. The sample was predominantly people with an established diagnosis (94\%), with a high proportion (56\%) of people with uncontrolled epilepsy (time since last seizure less than 1 month). Just under half had experienced recent changes to their AED regimen (within the last 3 months). Because of the very small numbers replying who reported a recent diagnosis of epilepsy, we do not present data on respondent characteristics separately for the recently diagnosed and established epilepsy subgroups (see Table 2).

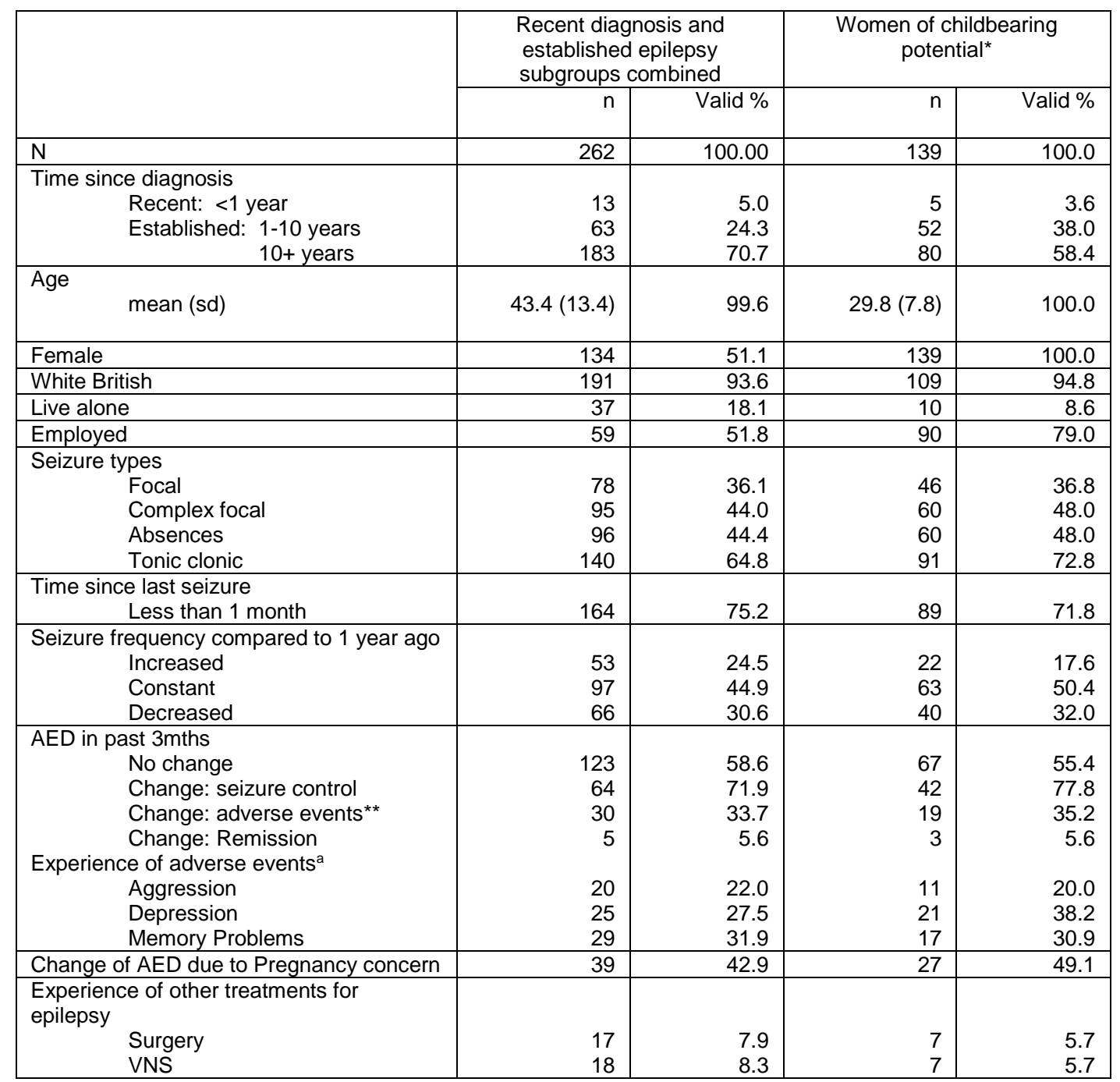

Table 2. Phase 2 respondent characteristics

Note. *Women of childbearing potential (those who responded "yes" to: "Is there any chance, however remote, that you may become pregnant in the future?"). Data are counts unless otherwise stated. **Described in questionnaire as "side-effects". aDue to a routing error in the questionnaire, only patients who had experienced a change in their AED in the past 3 months responded to the item on experience of adverse events.

Table 3 documents responses to the individual preference items relating to the treatment options of surgery, VNS, psychological support and complementary therapies (preferences relating to AEDs were dealt with separately in the DCE, see Holmes et al, 52). 


\begin{tabular}{|c|c|c|c|c|}
\hline Statement & $\begin{array}{c}\mathbf{N} \\
\begin{array}{c}\text { responders } \\
\text { to } \\
\text { statement }\end{array}\end{array}$ & $\begin{array}{c}\text { Agree } \\
\text { somewhat } \\
\%\end{array}$ & $\begin{array}{l}\text { Strongly } \\
\text { agree } \\
\%\end{array}$ & $\begin{array}{c}\text { Total } \\
\text { Agreement* } \\
\%\end{array}$ \\
\hline \multicolumn{5}{|l|}{ Surgery } \\
\hline $\begin{array}{l}\text { I would consider surgery if my seizures could not be } \\
\text { controlled by medication }\end{array}$ & 331 & 35 & 36.9 & 71.9 \\
\hline I would only ever consider surgery as a last resort & 330 & 32.1 & 33.6 & 65.8 \\
\hline $\begin{array}{l}\text { I would never want to have surgery because of the risks } \\
\text { involved** }\end{array}$ & 328 & 19.5 & 18 & 37.5 \\
\hline \multicolumn{5}{|l|}{ VNS } \\
\hline I would consider having VNS to help control my seizures & 330 & 30.3 & 27.3 & 57.6 \\
\hline $\begin{array}{l}\text { I would not want to try VNS because I think it is too } \\
\text { invasive }\end{array}$ & 328 & 11.9 & 8.5 & 20.4 \\
\hline \multicolumn{5}{|l|}{ Psychological support } \\
\hline $\begin{array}{l}\text { There is not enough psychological support available for } \\
\text { people with epilepsy }\end{array}$ & 325 & 22.2 & 51.7 & 73.8 \\
\hline $\begin{array}{l}\text { I would like to be offered psychological support to help } \\
\text { manage my epilepsy }\end{array}$ & 324 & 28.7 & 35.8 & 64.5 \\
\hline $\begin{array}{l}\text { I think psychological support should be more readily } \\
\text { available }\end{array}$ & 325 & 28.6 & 52.3 & 80.9 \\
\hline \multicolumn{5}{|l|}{ Support for memory problems } \\
\hline $\begin{array}{l}\text { I have problems with my memory and would like to know } \\
\text { what help is available }\end{array}$ & 327 & 26.6 & 54.7 & 81.3 \\
\hline \multicolumn{5}{|l|}{ Complementary therapies } \\
\hline $\begin{array}{l}\text { I would like to try yoga (in addition to taking medication) } \\
\text { to help me cope with having epilepsy }\end{array}$ & 328 & 25.6 & 22.6 & 48.2 \\
\hline $\begin{array}{l}\text { I would like to try acupuncture (in addition to taking } \\
\text { medication) to help me cope with having epilepsy }\end{array}$ & 326 & 18.7 & 12.6 & 31.3 \\
\hline $\begin{array}{l}\text { I would like to try meditation (in addition to taking } \\
\text { medication) to help me cope with having epilepsy }\end{array}$ & 326 & 27.3 & 18.1 & 45.4 \\
\hline $\begin{array}{l}\text { I would like to try aromatherapy (in addition to taking } \\
\text { medication) to help me cope with having epilepsy }\end{array}$ & 323 & 18.9 & 14.2 & 33.1 \\
\hline
\end{tabular}

Table 3: Agreement rates survey preference statements

*As described earlier, respondents were asked to answer each preference statement using a 5-point Likert response scale, 'strongly agree', 'agree somewhat ', 'don't know', 'disagree somewhat', 'strongly disagree'). For parsimony, only the \%s agreeing are shown here.

**It is interesting to note that some participants who said they would never want to have surgery because of the risks also indicated that they would consider surgery if their seizures were uncontrolled by AEDS.

The majority of survey respondents, over $70 \%$, stated that they would consider surgery if their seizures were not sufficiently well controlled by AEDs - but most (66\%) also saw surgery as a treatment of last resort; and almost two-fifths took the position that they would never want to have surgery because of the risks involved. Just over half of respondents would be willing to try VNS to control seizures. Around a half expressed interest in meditation and yoga as potentially useful approaches to coping with having epilepsy. Perhaps most importantly, three-quarters of survey respondents agreed that psychological support for people with epilepsy was lacking and should be made more readily available; with two-thirds keen to avail themselves of it. Equally important, over $80 \%$ wanted support to manage memory problems associated with having epilepsy. There were no statistically significant differences in the responses to these statements by women of childbearing potential or otherwise. 


\section{Discussion}

We used a combination of in-depth qualitative and large-scale quantitative approaches to investigate the expressed preferences for treatment of people with epilepsy, both recently diagnosed and established, and including a specific patient sub-group, women of childbearing age. The use of this methodological 'triangulation' (60) helps, we would argue, to enhance the trustworthiness of our findings (61), since the issues and concerns presented in the in-depth accounts of Phase 1 participants were then subject to scrutiny by the much larger number of survey respondents. Their subsequent endorsement of key themes identified in the qualitative phase increases the overall robustness of our conclusions. Thus, for example, the concerns expressed by phase 1 study participants about the risk of harm associated with different treatments were echoed by respondents to the survey. Likewise, there was support from both phases of the study for greater provision of psychological and neuropsychological support.

From our qualitative study, key drivers for treatment preferences were the desire to achieve seizure freedom and live 'a normal life'. Whilst, in general, experiencing some negative treatment effects was considered a tolerable trade-off for seizure control (see Holmes et al, 52) risk of harm was a key concern; and there was a tipping point where the adverse consequences of treatment were seen to outweigh any benefits. For example, surgery was often viewed as particularly risky and a last resort treatment due to its potentially catastrophic consequences - a finding reinforced by the survey, where two-thirds agreed with the statement that they would only ever consider surgery as a last resort.

Our qualitative study involved 22 women defined as of childbearing potential. Supporting what has been reported elsewhere in the literature (59) weighing up the benefits versus the risk of harms of treatment was particularly complex for these women - who had to assess potential risks, not only to themselves but also to an unborn child. Whilst they, like other participants, had generic concerns about treatment options and health care provision more broadly, their decisions concerning treatment in the context of epilepsy were inherently more complex. Our data highlight once again the need in this group for provision of advice on appropriate contraception, the risks of pregnancy with regard to foetal outcomes, and what represents appropriate AED medication. Optimal provision of such advice can only be realised if women have access to the relevant specialists before, throughout and after pregnancy.

Among possible options for managing life with epilepsy, psychological support broadly and support for memory problems specifically, were highlighted as important aspects of treatment currently of very limited availability. Participants in both phases of the study were keen to stress the need for better provision of these two treatment options. Large numbers of participants across the two study phases were also interested in accessing complementary therapies such as yoga, meditation, aromatherapy, and traditional Chinese medicines.

\section{Limitations of our study}

Our conclusions are limited by the relatively small number of participants involved in the second phase of our study. For the qualitative investigation, we aimed to recruit 60 individuals, in order to reach data saturation; and in the event, we achieved a sample size of 56 . For the survey, however, from a potentially very large sample (the EA membership database) only 401 individuals responded; and analysis showed that responders tended to be people with established epilepsy of some duration, who were likely experiencing frequent seizures $(56 \%$ had had a seizure in the previous 
month) and had switched medications recently, most often owing to lack of efficacy. As has often been argued to be the case in surveys drawing on patient support group membership, it may be that they responded to EA's request for participation for the reason that they were individuals whose epilepsy was particularly problematic for them. Further, a significant number (approximately 20\%) who completed the DCE that formed the first part of the survey failed to continue with completion of the section relating to treatment experiences and preferences, perhaps because the DCE was of itself quite a lengthy exercise. The survey was an online one, so completion was dependent on access to the internet; and the sample was a self-selected one. Thus, for a number of reasons the generalizability of our findings may be compromised.

Further, in both the qualitative study and the survey, those individuals with established epilepsy would almost inevitably have had more life and treatment experiences to inform their views and preferences than those only recently diagnosed. There is evidence from elsewhere (62), albeit in the context of systems of healthcare rather than specific treatments, that having preferences is problematic if a person has not experienced the different possible alternatives under comparison, since 'consumers do prefer what they know'. Additionally, treatment preferences are not static, but may change both over time and as a result of treatment experience (63). Even among our participants with established epilepsy, relatively few had experience of surgery or VNS; or of treatments aimed less at managing seizures than managing epilepsy as a lived experience. This needs also to be borne in mind when interpreting our findings.

Not withstanding these limitations, we would suggest that our study is one of few to explore in depth the treatment preferences of people with epilepsy. Our findings make clear that patient views about the value of and their preferences for treatment need to be considered within their individual life context - which will include gender, epilepsy history and characteristics, the physical, psychological and life impacts of epilepsy and everyday life circumstances (including life roles and responsibilities).

\section{How can patient preferences be addressed?}

In considering the answer to the above question, we focus here on what our study has to say about non-AED treatment options, since patient preferences around AEDs is dealt with in detail elsewhere $(52,62)$. Despite the limitations previously discussed, there are a number of key messages from this study, with implications for patient care. First, exploration of the possibility of surgery for epilepsy as a treatment option has highlighted considerable resistance to its use among participants, except in a situation of 'last resort'. Yet, it has been argued that surgery should not be reserved as an option to be invoked only when all else fails $(65,66)$. Evidence suggests that not only patients, but clinicians also, may take this position, with the result that individuals with pharmaco-resistent epilepsy may be subjected to many years of poor seizure control before surgery is proposed. Engel et al (65) note that typically, patients are referred for surgery too late to avoid significant disability (and, it follows, significant decrements in quality of life). Yet, in the randomised trial these authors report, of early surgery in patients with disabling seizures persisting for a maximum of two years following trials of two AEDS, 11 of 15 in the surgical group compared to none on the medical group were seizure-free during a two-year follow-up period. There was also a (non-significant) improvement in their QOL scores, compared to the medical controls. These findings support Gilliam's (67) comment that patients need to be given adequate information regarding the relative risks of undergoing surgery compared to experiencing recurrent seizures, in order to make fully informed choices. Engel (68) notes that technological advances have made surgery a much safer and more efficacious treatment 
option; and this is a message that, our findings would suggest, needs greater discussion with potential patient candidates, allowing them to better appreciate its role in epilepsy management.

Engel (69) has made the point that for patients unwilling to consider or judged unsuitable for surgery, 'a variety of treatments' are still available. Among those he cites include ones identified of interest to participants in our study - namely, complementary therapies and psychological support as a means of dealing with the stress of their condition and helping to come to terms with it. In our survey, almost four-fifths of participants commented on the paucity of psychological support services; and over three-fifths commented on their wish that they themselves be offered such support. Thus, our study has identified an area of large unmet need. Though we did not question participants at either phase of the study about their psychological status, anxiety and depression are known to be the commonest co-morbidities in epilepsy $(70,71)$, both potentially responsive to appropriate treatment $(19,23,24,26,72)$. By way of example, the UPLIFT programme (73) used CBT delivered by phone and internet in adults with epilepsy with mild to major depression and reported a significant reduction in the incidence of major depression in the active intervention group. The current lack of such psychological support is therefore an issue of considerable concern.

Most common among the co-morbidities after anxiety and depression are neuropsychological problems, in particular problems with memory. In our own study, memory problems were reported by almost a third of survey respondents; and they valued reduction in the risk of memory problems more highly than improvements in the probability of seizure remission (52). There are multiple potential causes of memory problems in epilepsy - they may be associated with the type of underlying lesion or seizures; they may be a side-effect of AEDs; or they may be secondary to mood disorders (74). Possible explanations for memory problems therefore need unpicking at an individual patient level. Patients consistently report memory problems as significant $(75,76)$; but, unfortunately, despite patients' concerns they are not routinely addressed in clinical practice. The most significant reason for the poor provision of memory rehabilitation programmes - at least in the UK - is the lack of availability of neuropsychological services (Baker, personal communication); but PWE may also be too ready to accept memory decrements as an inevitable outcome of epilepsy and therefore fail to seek appropriate support. Nonetheless, in our study, over $80 \%$ of participants in the survey reinforced the clear message from interview informants about the lack of provision and the need for greater investment in this treatment option.

Finally, despite that the lack of evidence of effectiveness was highlighted in the patient information provided and though they did not see complementary therapies as contributing directly to seizure control, significant numbers of participants in both phases of the study expressed interest in them as a means to help them to cope with their epilepsy. In the qualitative study, most frequently mentioned were meditation, yoga, aromatherapy and acupuncture. In the survey, a third of respondents were interested in aromatherapy, and just under a half in yoga and meditation. One question this raises is to what degree patients are aware that there may be some costs, as well as benefits from the use of complimentary therapies; and that evidence in support of their use is currently very sparse. The UK Epilepsy Society provides information to patients about the different complimentary therapies in which it highlights that some can potentially increase the risk of seizures (https://www.epilepsysociety.org.uk/complementary-therapies; accessed 5 March 2017) - so patients need to know as much as possible about them. In particular, in the context of our study participants' preferences, they note that some essential oils used in aromatherapy are not recommended as they may trigger seizures. The authors of a Cochrane Review (77) concluded, based on 17 randomised trials involving over 1500 individuals, that compared to AEDs alone, needle 
acupuncture and catgut implantation at acupoints in combination with AEDs was ineffective in achieving seizure freedom, but may be better in achieving satisfactory seizure control. However, since the trials considered were small and with high risks of bias, the conclusion was that 'it remains uncertain whether acupuncture is effective and safe for treating PWE.' Yoga for epilepsy was considered, also in a Cochrane Review (78), which included two randomised trials involving 50 adults with refractory epilepsy and suggested possible beneficial effects in relation to seizure control. However, again, the authors concluded that the evidence was insufficient to support its use and that further trials are needed. Finally, a non-randomised study has recently been conducted of the role of meditation as a treatment for epilepsy (https://clinicaltrials.gov/ct2/show/NCT00370929; accessed 5 March 2017), in which the outcomes of interest are not only seizure frequency, but also quality of life and specific QOL domains (mood, affect, sleep quality) - these latter outcomes being the ones of particular interest to our own study participants. However, no results have been published as yet. Though use of complementary therapies may have little impact on seizure frequency, at least directly, they may have other important benefits for quality of life in PWE, which needs confirmation through conduct of robust clinical trials.

In conclusion, we would suggest that our study bears witness to the need to understand how patient preferences for care align to their personal characteristics and life contexts (39). The author of the study alluded to above has commented that epilepsy is a complex condition treatment of which, 'relies on precise understanding of patient characteristics' (79). Adoption of an 'ecological model' (80) of patient preferences emphasises that preferences, 'emerge from various contexts' including not just the clinical encounter, but also family and media exposure. Our study supports these arguments. It also emphasises the importance of ensuring that treatment options responsive to patient preferences are adequately investigated and those for whom evidence of utility can be shown are made more readily available.

\section{Acknowledgements}

The research reported here was funded by the UK National Institute for Health Research (NIHR) under its Research for Patient Benefit (RfPB) Programme (Grant Reference Number PB-PG-090920161). AM is part funded by NIHR Collaboration for Leadership in Applied Health Research and Care North West Coast (NIHR CLAHRC NWC). The views expressed are those of the author(s) and not necessarily those of the NHS, the NIHR or the Department of Health.

We thank staff and members of Epilepsy Action and members of Epilepsy Action Research Volunteers Network (EARNs) for their invaluable contribution to the research through their support, advice and feedback on various aspects of the work. Particular thanks are due to Margaret Rawnsley at Epilepsy Action for her contribution to the development of the funding bid.

We thank the members of our study Advisory Group, who gave much time and thought to the issues that arose during its conduct: Carole Brown, Jeff Canning, Jo Coast, Paul Cooper, Margaret Jackson, Andrew Kirkham, Helen Lowe, Doug McCorry, Rajiv Mohanraj.

We thank all those people with epilepsy who contributed to the research through interviews or completion of the survey. We hope the data thus generated will support the development of more patient-focussed care and greater emphasis on the satisfaction of their individual care needs. 


\section{References}

1. National Institute for Health Research. NIHR Programme Grants for applied research: invitation to submit outline application. London, National Institute for Health Research, 2006.

2. Forsgren L, Beghi E, Oun A, Sillanpää M. The epidemiology of epilepsy in Europe - a systematic review. Eur J Neurol, 2005, 12: 245-53.

3. Epilepsy Action. Epilepsy facts, figures and terminology. https://www.epilepsy.org.uk/press/facts, July 2015.

4. Hauser, W. A., et al. Seizure recurrence after a first unprovoked seizure: an extended followup. Neurology, 1990, 40: 1163-70.

5. Cockerell, O. C., et al. Remission of Epilepsy - Results from the National General- Practice Study of Epilepsy. The Lancet, 1995, Vol. 346, ps. 140-44, 15 July.

6. Jacoby, A., Baker, G., Snape, D. Epilepsy and social identity: the stigma of a chronic neurological disorder. Lancet Neurology, 2005, 4: 171-78.

7. Jacoby, A., Baker, G.A. Quality-of-life trajectories in epilepsy: A review of the literature. Epilepsy \& Behavior, 2008, 12(4): 557-71.

8. Morrow, J., et al. Malformation risks of antiepileptic drugs in pregnancy: a prospective study from the UK Epilepsy and Pregnancy Register. Journal of Neurology Neurosurgery and Psychiatry, 2006, 77 (2): 193-98.

9. Meador K, Baker G, Browning N, et al. Fetal antiepileptic drug exposure and cognitive outcomes at age 6 years (NEAD study): a prospective observational study. Lancet Neurology, 2013, 12: 244-52.

10. Bromley R, Weston J, Adab N, Greenhalgh J, Sanniti A et al. Treatment for epilepsy in pregnancy: neurodevelopmental outcomes in the child (Review). The Cochrane Library, 2014, Issue 10.

11. Weston J, Bromley R, Jackson CF, Adab N, Clayton-Smith J, Greenhalgh J, Hounsome J, McKay AJ, Tudur Smith C, Marson AG. Monotherapy treatment of epilepsy in pregnancy: congenital malformation outcomes in the child. Cochrane Database of Systematic Reviews, 2016, Issue 11. Art. No.: CD010224. DOI: 10.1002/14651858.CD010224.pub2

12. Engel, J., Jr., Wieser, H.G., Spencer, D.D. Overview: Surgical Therapy. In Epilepsy $A$ Comprehensive Textbook. Ed. Engel, J. Jr.,Pedley, T.A. 2nd ed. ed. Philadelphia: Lippincott Williams \& Wilkins, 2008, ps.1747-49.

13. Schachter, S. C., Boon P. Vagus Nerve. In Epilepsy A comprehensive Textbook. Ed. Engel J Jr, Pedley T.A. 2nd ed. Philadelphia: Wolters Kluwer-Lippincott Williams \& Wilkins, 2008, ps.1395-99.

14. Stafstrom, C. E., Vining, P.G., Rho J.M. Ketogenic Diet. In Epilepsy A comprehensive textbook. Ed. Engel, J. Jr., Pedley, T.A. Second ed. Philadelphia: Lippincott Williams \& Wilkins, 2008, ps. 1377-94.

15. Neal, E G., et al. The ketogenic diet for the treatment of childhood epilepsy: a randomised controlled trial. The Lancet Neurology, 2008, 7(6): 500-06.

16. Martin K, Jackson CF, Levy RG, Cooper PN. Ketogenic diet and other dietary treatments for epilepsy. Cochrane Database of Systematic Reviews, 2016, Issue 2. Art. No.: CD001903. DOI: 10.1002/14651858.CD001903.pub3.

17. Ramaratnam, S., Baker G., Goldstein, L.H. Psychological treatments for epilepsy. Cochrane Database of Systematic Reviews 4 (2005).

18. Cross, H. Behavioural and psychological treatments for epilepsy: Cognitive behavioural therapy. http://bestpracice.bmj.com/best-practice/evidence/intervention/1214/0/sr-1214i4.html. Accessed 6 March 2017.

19. Tang V, Poon WS, Kwan P. mindfulness-based therapy for drug-resistant epilepsy. An assessor-blinded randomised trial. Neurology, 2015, DOI: http://dx.doi.org/10.1212. 
20. Sathyaprabha, T. N., et al. Modulation of cardiac autonomic balance with adjuvant yoga therapy in patients with refractory epilepsy. Epilepsy \& Behavior, 2008, 2(2): 245-52.

21. Wang, S., Li Y. Traditional Chinese Medicine. In Complementary and Alternative Therapies for Epilepsy. Ed. Devinsky, O., Schachter, S., Pacia S. York: Demos Medical Publishing, 2005, ps. 177-82.

22. May, T. W., Pfafflin, M. The efficacy of an educational treatment program for patients with epilepsy (MOSES): Results of a controlled, randomized study. Epilepsia 2002, 43(5): 539-49.

23. Thompson, NJ, Walker ER, Obolensky N, Winning A, Barmon c et al. Distance delivery of mindfulness-based cognitive therapy for depression: project UPLIFT. Epilepsy \& Behavior 2010, 19: 247-54.

24. Ciechanowski P, Chaytor N, Miller J, Fraser R, Russo J et al. PEARLS depression treatment for individuals with epilepsy: $s$ randomised controlled trial. Epilepsy \& Behavior 2010, 19: 225-31.

25. Dilorio C, Bamps Y, Walker ER, Escoffery C. Results of a research study evaluating Webease, an online epilepsy self-management program. Epilepsy \& Behavior 2011, 22: 4769-74.

26. Gandy M, Sharpe L, Perry KN. Cognitive behabvior therapy for depression in people with epilepsy: a systematic review. Epilepsia 2013, 54(10): 1725-34.

27. Laybourne AH, Morgan MA, Watkins S, Lawton R, Ridsdale LL, Goldstein LH. Self-management for people with poorly controlled epilepsy: Participants' views of the UK Self-Management in epILEpsy (SMILE) program. Epilepsy \& Behavior, 2015, 52: 159-64.

28. Langfitt, J. T., et al. Worsening of quality of life after epilepsy surgery - Effect of seizures and memory decline. Neurology, 2007, 68(23): 1988-94.

29. Spencer, S. S., et al. Health-related quality of life over time since resective epilepsy surgery. Annals of Neurology, 2007, 62(4): 327-34.

30. Uthman BM. Vagus nerve stilulation for seizures. Arch Med Res 2000, 31: 300-303.

31. Rogovik AL, Goldman RD. Ketogenic diet for treatment of epilepsy. Can Fam Physician 2010, 56: 540-42.

32. Rothwell, P. M., et al. Doctors and patients don't agree: cross sectional study of patients' and doctors' perceptions and assessments of disability in multiple sclerosis. British Medical Journal, 1997, 314: 1580-83.

33. Kwoh, C. K., Ibrahim, S.A. Rheumatology patient and physician concordance with respect to important health and symptom status outcomes. Arthritis \& Rheumatism-Arthritis Care \& Research, 2001, 45(4): 372-77.

34. Kvien, T. K., Heiberg T. Patient perspective in outcome assessments - Perceptions or something more? Journal of Rheumatology, 2003, 30(4): 873-76.

35. Bury, M., Taylor D. Towards a Theory of Care Transition: from Medical Dominance to Managed Consumerism. Social Theory \& Health, 2008, 6: 201-19.

36. Department of Health. The National Service Framework for long term conditions. 265109, 1102. London, 2005.

37. NICE: National Institute for Health and Care Excellence Medicines, Prescribing Centre. Medicines optimisation: the safe and effective use of medicines to enable the best possible outcomes. Manchester: National Institute for Health and Care Excellence; 2015.

38. Coulter, A. and Redding, D. (2007). Patient-centred care. Personal best: put the customer in control. Health Serv J, 117, 20-21.

39. van Hoorn R, Kievit W, Booth A, Mozygemba K, Lysdahl KB, et al. The development of PubMed search strategies for patient preferences for treatment outcomes. BMC Medical Research Methodology 2016, 88. DOI: 10.1186/s12874-016-0192-5.

40. Birbeck GL, Hays RD, Cui XP, Vickrey BG. Seizure frequency and quality of life improvements in people with epilepsy. Epilepsia 2002, 43: 535-58.

41. Noble AJ, Marson AG. Which outcomes should we measure in adult epilepsy trials? The views of people with epilepsy and informal carers. Epilepsy \& Behaviour, 2016, 59:105-10.

42. Dilorio, C. Preferences concerning epilepsy education; opinions of nurses, physicians, and persons with epilepsy. Journal of Neuroscience Nursing, 1995, 1: 29-34. 
43. Mills, N., et al. Patients' experience of epilepsy and health care. Family Practice, 1997, 14(2): 117-23.

44. Poole, K., et al. Patients' perspectives on services for epilepsy: a survey of patient satisfaction, preferences and information provision in 2394 people with epilepsy. Seizure, 9(8): 551-58.

45. Lloyd, A., McIntosh, E., Price, M. The importance of drug adverse effects compared with seizure control for people with epilepsy - A discrete choice experiment. Pharmacoeconomics, 2005, 23(11): 1167-81.

46. Werz, M. A., et al. Subjective preference for lamotrigine or topiramate in healthy volunteers: Relationship to cognitive and behavioral functioning. Epilepsy \& Behavior 8.1 (2006): 181-91.

47. Manjunath R, Yang JC, Ettinger AB. Patients' preferences for treatment outcomes of add-on antiepileptic drugs: a conjoint analysis. Epilepsy \& Behavior, 2012, 24(4): 474-9.

48. Shaw, E. J., et al. Self-management education for adults with epilepsy. Cochrane Database Syst Rev.2, 2007: CD004723.

49. Bradley, P. M., Lindsay B. Care delivery and self-management strategies for adults with epilepsy. Cochrane Database of Systematic Reviews, 2008.

50. Mattingly C, Garro L. Narrative and Cultural Construction of IIIness and Healing. University of California Press, 2000.

51. Holloway W, Jefferson T. Doing Qualitative Research Differently. SAGE, 2000.

52. Holmes E, Plumpton C, Baker G, Jacoby A, Ring A, Williamson P, Marson A, Hughes D. Patientfocused drug development methods for benefit-risk assessments: A case study using discrete choice experiment for antiepileptic drugs. Clinical Pharmacology \& Therapeutics 2018, 105 (3): 672-683.

53. Kuzel, AJ. Sampling in Qualitative Inquiry. In: Crabtree BF, Milller WL. Doing Qualitative Research $2^{\text {nd }}$ Edition. Thousand Oaks, California. Sage Publications Inc. 1999, ps.33-45.

54. Richards, L. Data alive! The thinking behind NVivo. Qualitative Health Research 1999, 9 (3): 412-428.

55. Corbin J, Strauss A. Basic of qualitative research: techniques and procedures for developing grounded theory. Thousand Oaks, CA: Sage Publications, 2008.

56. Glaser BG, Strauss AL. The Discovery of Grounded Theory. Chicago: Aldine, 1967.

57. Jacoby A, Baker GA. Quality of life trajectories in epilepsy. Epilepsy \& Behavior 2008, 12(4): 557-71.

58. Jacoby A, Ring A, Whitehead M, Marson AG, Baker GA. Exploring loss and replacement of loss for understanding the impacts of epilepsy onset: A qualitative investigation. Epilepsy \& Behavior 2014, 33: 59-68.

59. Winterbottom J. Women with epilepsy preparing for pregnancy: A qualitative analysis. PhD Thesis: University of Liverpool, 2012.

60. Patton, MQ. Designing Qualitative Studies In Patton MQ ( $\left.2^{\text {nd }} E d\right)$ Qualitative Evaluation and Research Methods. Newbury Park, California: Sage Publications Inc., 1990, ps.187-198.

61. Lambert SD, Loiselle CG. Combining individual interviews and focus groups to enhance data richness. Journal of Advanced Nursing 2008, 62(2): 228-37.

62. Hundley V, Ryan M. Are women's expectations and preferences for intrapartum care affected by the model of care on offer? British Journal of Obstetrics \& Gynaecology 2004, 111: 550-60.

63. Schaarschmidt ML, Umar N, Schmieder A, Terris DD, Goebeler M. Patient preferences for psoriasis treatments: impact of treatment experience. Journal of European Academy of Dermatology \& Venereology 2013, 27: 187-98.

64. Powell G, Holmes EAF, Plumpton CO, Ring A, Baker GA, Jacoby et al. Pharmacogenetic testing prior to carbamazepine treatment of epilepsy: patients' and physicians' preferences for testing and service delivery. British Journal of Clinical Pharmacology 2015, 80(5): 1149-59.

65. Engel J Jr. Early surgical therapy for drug-resistant temporal lobe epilepsy: a randomised trial. JAMA 2012, 307(9): 922-30.

66. Kingwell K. Epilepsy: Surgical therapy should not be considered a last resort for pharmacoresistant eepilepsy. Nature Reviews Neurology, 2012, 8:238. 
67. Gilliam F. Optimising health outcomes in active epilepsy. Neurology, 2002, 58(8): Suppl.5, S9.

68. Engel J Jr. Who will use epilepsy surgery nomograms, and why? Lancet Neurology, 2015, 14(3): 240-41.

69. Engel J Jr. Approaches to refractory epilepsy. Ann Indian Neurology, 2014, 17(Suppl 1): S1217.

70. Tellez-Zenteno J. F., Patten S. B., Jetté N., Williams J., Wiebe S. Psychiatric comorbidity in epilepsy: A population-based analysis. Epilepsia, 2007, 48: 2336-2344.

71. Kanner AM. Anxiety disorders in epilepsy: the forgotten psychiatric comorbidity. Epilepsy Curr, 2011, 11(3): 90-91.

72. McLaughlin DP, McFarland K. McLaughlin DP, McFarland K. A randomized trial of a group based cognitive behavior therapy program for older adults with epilepsy: the impact on seizure frequency, depression and psychosocial well-being. Journal of Behavioral Medicine, 2011, 34(3): 201-7.

73. Thompson NJ, Patel AH, Selwa LM, Soll SC, Begley CE Johnson EK et al. Expanding the efficacy of project UPLIFT: distance delivery of mindfulness-based depression prevention to people with epilepsy. Journal Consult Clin Psychol, 2015, 83(2): 304-13.

74. Corcoran R, Thompson P. Memory failure in epilepsy: retrospective reports and prospective recordings, Seizure, 1992,1: 37-42.

75. Vermeulan J, Aldenkamp AP, Alpherts WCJ. Memory complaints in epilepsy: correlations with cognitive performance and neuroticism. Epilepsy Research, 1993, 15(2): 157-70.

76. Butler CR, Zeman AZ. Recent insights into the impairment of memory in epilepsy: transient epileptic amnesia, accelerated long-term forgetting and remote memory impairment. Brain, 2008, 131(9): 2243-63.

77. Cheuk DKL, Wong V. Acupuncture for epilepsy. Cochrane Database of Systenatic Reviews 2014, Issue 5: CD005062.

78. Panebianco M, Sridharan K, Ramaratnam S. Yoga for epilepsy. Cochrane Database of Systematic Reviews 2015, Issue 5: CD001524.

79. Stern JM, Laniner DM, Gilliam FG, Penovich PE, Onofrey M et al. More effective assessment of adverse effects and comorbidities in epilepsy: Results of a Phase II communication study. Epilepsy \& Behavior , 2011, 22: 552-56.

80. Street RL, Elwyn G, Epstein RM. Patient preferences and healthcare outcomes: an ecological perspective. Expert Reviews of Pharmacoeconomics \& Outcomes Research, 2012, 12: 2. 
Appendix 1: Examples of treatment interventions and evidence of effectiveness

\begin{tabular}{|c|c|c|}
\hline Medical & Definition & Effectiveness \\
\hline Surgery for epilepsy & $\begin{array}{l}\text { 'There are many different types of } \\
\text { surgery for epilepsy. The type of surgery } \\
\text { depends on the type of seizures and the } \\
\text { area of the brain where seizure begins'. } \\
\text { (Epilepsy Action) }\end{array}$ & $\begin{array}{l}\text { Surgery is effective in reducing the } \\
\text { frequency of seizures and stopping } \\
\text { seizures altogether in some cases. } \\
\text { However, the success of surgery is } \\
\text { dependent on the type of epilepsy } \\
\text { and the type of surgery (Spencer and } \\
\text { Huh, 2008). }\end{array}$ \\
\hline $\begin{array}{l}\text { Vagal nerve stimulation } \\
\text { (VNS) }\end{array}$ & $\begin{array}{l}\text { 'Vagus nerve stimulation (VNS) uses a } \\
\text { small generator that is implanted under } \\
\text { the skin below the collar bone. This is } \\
\text { connected to a lead with two coils at one } \\
\text { end. The coils are wrapped around the } \\
\text { vagus nerve at the side of the neck, under } \\
\text { the skin, during a small operation. The } \\
\text { generator sends electrical impulses, at } \\
\text { intervals, to the vagus nerve and then to } \\
\text { the brain'. (Epilepsy Action). }\end{array}$ & $\begin{array}{l}\text { Current evidence suggests that } \\
\text { around two thirds of people } \\
\text { receiving VNS, experience } 30 \% \text { or } \\
\text { greater improvement in seizure } \\
\text { frequency. Seizure improvement } \\
\text { following VNS is not significantly } \\
\text { greater then seizure improvement } \\
\text { with medication (Vonck et al, 2009). }\end{array}$ \\
\hline \multicolumn{3}{|l|}{ Psychologically based } \\
\hline $\begin{array}{l}\text { Cognitive behavioural } \\
\text { therapy (CBT) }\end{array}$ & $\begin{array}{l}\text { 'CBT is a problem-focused talking } \\
\text { therapy. CBT helps people to identify } \\
\text { problems and difficulties in their life and } \\
\text { to resolve those difficulties by breaking } \\
\text { them down into their smaller parts } \\
\text { (situation, thoughts, emotions, physical } \\
\text { feelings and actions) and by changing } \\
\text { individual thinking and behaviour and } \\
\text { emotional response'. (ACT; RCPsych) }\end{array}$ & $\begin{array}{l}\text { There is some evidence that CBT may } \\
\text { be beneficial for treating epilepsy } \\
\text { and its co-morbidities (McLaughlin } \\
\text { and Farland, 2011). There are many } \\
\text { different psychological therapies and } \\
\text { lack of consistency across studies has } \\
\text { made establishing treatment } \\
\text { effectiveness difficult (Ramaratnam } \\
\text { et al, 2008). }\end{array}$ \\
\hline \multicolumn{3}{|l|}{ Complementary } \\
\hline Yoga & $\begin{array}{l}\text { 'Yoga is a physical, mental and spiritual } \\
\text { discipline' (Wiki). Different types of Yoga } \\
\text { involve concentration on breathing } \\
\text { (controlled breathing), physical exercise } \\
\text { (stretching and flexing - posture) and } \\
\text { meditation and relaxation (Epilepsy } \\
\text { Action \& byw). }\end{array}$ & $\begin{array}{l}\text { Whilst there is some evidence for the } \\
\text { possible beneficial effects of Yoga for } \\
\text { epilepsy (Yardi, 2001; Lundgren et } \\
\text { al., 2008), evidence remains very } \\
\text { limited (McElroy-Cox, 2009). }\end{array}$ \\
\hline Acupuncture & $\begin{array}{l}\text { 'Acupuncture involves treating the whole } \\
\text { person, body and mind, by using needles, } \\
\text { and sometimes heat, to stimulate the } \\
\text { nerve endings. The aim is to improve the } \\
\text { general state of health, creating a better } \\
\text { mental, physical and emotional balance' } \\
\text { (Epilepsy Action). }\end{array}$ & $\begin{array}{l}\text { Whilst case study evidence suggests } \\
\text { potential benefits of acupuncture } \\
\text { (Yang \& Cheng, 2010), there is no } \\
\text { evidence from more robust research } \\
\text { methods to support effectiveness of } \\
\text { acupuncture in treating epilepsy } \\
\text { (McElroy-Cox, 2009). }\end{array}$ \\
\hline
\end{tabular}

